Research Article

\title{
Numerical Simulation of Helicopter Rotor Performance Degradation in Natural Rain Encounter
}

\author{
Guozhi Li ${ }^{1}{ }^{1}$ and Yihua Cao $(\mathbb{D})^{2}$ \\ ${ }^{1}$ Institute of Systems Engineering, Aviation Industry Development Research Center of China, Beijing 100029, China \\ ${ }^{2}$ School of Aeronautic Science and Engineering, Beihang University, Beijing 100191, China \\ Correspondence should be addressed to Yihua Cao; yihuacaobhu62@163.com
}

Received 19 February 2021; Revised 27 March 2021; Accepted 13 April 2021; Published 29 April 2021

Academic Editor: Jacopo Serafini

Copyright (c) 2021 Guozhi Li and Yihua Cao. This is an open access article distributed under the Creative Commons Attribution License, which permits unrestricted use, distribution, and reproduction in any medium, provided the original work is properly cited.

\begin{abstract}
Sustained flight operation in the rain conditions is still a challenge to a pilot. This problem can be mainly attributed to the aerodynamic performance degradation of aircraft. In this article, in order to quickly understand the influence of rainfall aiming at the engineering application, an approach to predict helicopter rotor performance degradation in heavy rain encounters is presented. Firstly, we develop a computational fluid dynamics- (CFD-) based method of simulation of the blade airfoil under natural rain scenario and different angles of attack in order to obtain a data-driven basis relating to multiple working conditions of the rotating blades for further analysis. Then, these data are studied using a discretization analysis method of rotor aerodynamics. CFD simulations are conducted, including the case of NACA 0012 airfoil with $10 \mathrm{~m}$ chord length, and the case of SC1095 airfoil used in a full-scale rotor of UH-60A helicopter. Prediction of helicopter rotor performance degradation is carried out in a thunderstorm heavy rain with the rain rate of $1500 \mathrm{~mm} / \mathrm{h}$ using this full-scale rotor. The quantitative results indicate that heavy rain dramatically degrades the rotor performance. The maximum percentage decrease in lift coefficient of this fullscale rotor blade airfoil is reached by $12.75 \%$. The maximum percentage increase in drag coefficient of this full-scale rotor blade airfoil is reached by $26.51 \%$. The maximum percentage decrease in averaging lift-to-drag ratio of this full-scale rotor disk is reached by $26.39 \%$.
\end{abstract}

\section{Introduction}

Rainfall has been also considered an important meteorological factor, apart from ice accretion, to threat flight safety [1]. Researchers have been conducting a series of studies on this subject. Early researches began in 1941 [2] with conclusions that it was not enough to make aircraft fall and crash because of little effect on the aircraft aerodynamic penalties due to rainfall, except for blurring pilot's line of sight, possibly leading to failure of the instruments, etc. In the next 40 years, a small number of published reports were focused on the problems of the influence of rainfall on flight. Until the 1980s, more and more flight accidents $[3,4]$ caused by rainfall indicated that researchers should reunderstand the influence of rainfall on flight. Thus far, sustained flight operations in heavy rain conditions are still a challenge to a pilot, according to the Aviation Weather Accidents Database (AWAD) [5].
Some of the research results [6-8] indicated that drag and lift penalties are very significant once the rain rate exceeds $100 \mathrm{~mm} / \mathrm{h}$, and a rain-roughened airfoil could suffer a decrease in stall angle with maximum lift coefficient reduction. The furthering research results [9] show that the premature boundary-layer transition at low angle of attack (AOA) and the separation at high AOA might be contributed to the aircraft aerodynamic penalties in natural rain encounters.

Numerical studies of the effects of rainfall on aircraft performance were early proposed in 1984 [10] by using a twodimensional N-S equation. However, the results were very different from what was tested due to considering only the volume force of the raindrops. In recent 10 years, further considering the effects of water film on the aerodynamics of the airfoil $[11,12]$, the results were increasingly close to the test. With the application of the two-phase flow approach to rainfall researches [13-16], studies [17] on the 
aerodynamic performance of helicopter rotor blade in the rain conditions concluded that rainfall would induce some detrimental effects on the main rotor blade's performance, and a $4 \mathrm{~mm}$ droplet size heavy rain has the most severe impact on the helicopter rotor blade. However, there is still lack of in-depth theoretical and engineering analysis and detailed results in order to quickly understand the effects of rainfall on the rotor and the helicopter flight performance and in order to conduct the assessment of the helicopter flight safety in rain environment. Thus far, few published literatures have been focused on the problems of the helicopter rotor encounters with rainfall. Thus, more efforts are still needed to conduct further research.

Actually, when a flying helicopter enters airspace with a high liquid water content, it is easy to encounter rainfall. When the raindrops impact on the rotor blade surface, the raindrops may adhere to the rotating blade surface and form into a thin water film. Once the environment temperature becomes low, this thin water film might quickly form into ice. Thus, there are some similarities and differences between helicopter encountering rainfall and ice accretion. These main differences are that the thin water film is flowing in the rain conditions and the thin water film forms into an ice layer that adheres to the blade surface due to thermodynamics effect in the icing conditions. Another difference is that the mean volumetric diameter of the droplet in the icing conditions is much lower than that in the rain conditions, except for icing in the freezing rain conditions. Both the thin water film and the ice layer will inevitably affect the aerodynamic performance of the blade. Their simulation methods are similar with each other to some extent. Thus, we can take some experience of the helicopter icing research [18-20] to conduct rainfall research.

In addition, the influence of rainfall on the helicopter rotor performance is also similar to the situation of an aircraft encounters with rainfall [21-24], which depends on the rotor aerodynamic characteristics under the airraindrop two-phase flow field. However, computational fluid dynamics- (CFD-) based techniques might be only applied to conduct in-depth research on the air-raindrop two-phase flow field for a rotor due to the particularity of the rotor structure. But these lack the ability to thoroughly study the effects of rainfall on the rotor performance including the distribution of the lift-to-drag ratio of a rotor disk, the rotor torque, and required power. In literature [17], for example, it was still only generally concluded that different rain droplet size has the different quantitative effects on the rotor lift. On the contrary, traditional rotor aerodynamics analysis techniques, such as the rotor momentum theory, rotor blade element theory, and rotor vortex theory [25], can conduct a detailed study on the problems of rotor performance. But these lack the ability to analyze the rainfall effects on rotor performance.

The contribution to this article is as follows: First, a CFDbased method to simulate the blade airfoil under natural rain scenario and different angles of attack is effectively and thoroughly developed in order to obtain a data-driven basis relating to multiple working conditions of the rotating blades. It includes the solution to the air-raindrop two-phase flow field around the blade airfoil and the solution to the water film flow (that is, the formation of the water film, the water film roughness, and the raindrop splash). Then, in order to predict and analyze helicopter rotor performance degradation in the rain conditions, these data are studied by using a discretization analysis method of rotor aerodynamics analysis. The idea of the traditional rotor blade element theory is adopted to develop this discretization analysis method. Our present work aims at quickly understanding the influence of rainfall from the perspective of engineering application. It serves for rotor engineering design especially for analysis of helicopter flight performance, trim, stability, and controllability in rain conditions.

\section{CFD-Based Method}

2.1. Natural Rain Conditions. The rain rate $(R, \mathrm{~mm} / \mathrm{h})$, the liquid water content $\left(L W C, \mathrm{~g} / \mathrm{m}^{3}\right)$, the mean volumetric diameter of the raindrop $(M V D, \mathrm{~mm})$, and the terminal velocity of the raindrop $\left(V_{\mathrm{H}}, \mathrm{m} / \mathrm{sec}\right)$ are critical parameters related to the natural rainfall. In order to deduce the quantitative relationships of the $R, L W C$, and $M V D$, the following classical Marshall \& Palmer's size distribution of raindrops [26] is adopted as follows:

$$
\left\{\begin{array}{l}
N(D)=N_{0} \bullet e^{-I \cdot D} \\
I=n \cdot R^{-m}
\end{array}\right.
$$

where $D$ is the raindrop diameter in millimetres. $N(D)$ and $I$ indicate the raindrop size distribution and the rainfall type, respectively. $N_{0}, m$, and $n$ are empirically determined constants.

Then, $L W C$ and $M V D$ are deduced as follows:

$$
\begin{gathered}
L W C=\int_{0}^{\infty} \frac{\pi}{6} \rho_{\mathrm{w}} D^{3} \cdot N(D) \cdot \mathrm{d} D=\rho_{\mathrm{w}} N_{0} \pi n^{-4} R^{4 m} \times 10^{-6}, \\
M V D=\frac{\int_{0}^{\infty} D \cdot(\pi / 6) \rho_{\mathrm{w}} D^{3} \cdot N(D) \cdot \mathrm{d} D}{\int_{0}^{\infty}(\pi / 6) \rho_{\mathrm{w}} D^{3} \cdot N(D) \cdot \mathrm{d} D}=4 R^{m} / n,
\end{gathered}
$$

where $\rho_{\mathrm{w}}$ is the rainwater density.

According to reference [27], $V_{\mathrm{H}}$ is written as follows:

$$
V_{\mathrm{H}}=9.58 \bullet\left[1-e^{-\left(\frac{M V D}{1.77}\right)^{1.147}}\right] \bullet\left(\frac{\rho_{\mathrm{H}}}{\rho_{0}}\right)^{0.4},
$$

where $\rho_{0}$ and $\rho_{\mathrm{H}}$ are the air density at sea level and the air density at the helicopter flight altitude, respectively.

In this article, a thunderstorm heavy rain with $N_{0}=1400$, $n=3$, and $m=0.21$ referred to in reference [28] and $R=$ $1500 \mathrm{~mm} / \mathrm{h}$ referred to in reference [17] are selected as a natural rain condition.

2.2. Air-Raindrop Two-Phase Flow. Because the volume fraction of raindrops in the air phase is very low, it is reasonable to assume that the air phase affects the raindrop phase, but the raindrop phase does not affect the air phase. Thus, the unsteady Reynolds-Averaged Navier-Stokes (RANS) 
equations with the high Reynolds number Spalart-Allmaras (S-A) turbulence model can be solved independently by using the 1st-order implicit unsteady solver in order to obtain the air phase flow field around the 2D airfoil of the rotor blade.

The Governing Equations of the raindrop phase around the $2 \mathrm{D}$ airfoil of the rotor blade can be written as follows:

$$
\left\{\begin{array}{l}
\frac{\partial \bar{\rho}}{\partial t}+\frac{\partial\left(\bar{\rho} u_{x}\right)}{\partial x}+\frac{\partial\left(\bar{\rho} u_{y}\right)}{\partial y}=0 \\
\frac{\partial\left(\bar{\rho} u_{x}\right)}{\partial t}+\frac{\partial\left(\bar{\rho} u_{x} u_{x}\right)}{\partial x}+\frac{\partial\left(\bar{\rho} u_{y} u_{x}\right)}{\partial y}=F_{\mathrm{D}, \mathrm{x}} \\
\frac{\partial\left(\bar{\rho} u_{y}\right)}{\partial t}+\frac{\partial\left(\bar{\rho} u_{x} u_{y}\right)}{\partial x}+\frac{\partial\left(\bar{\rho} u_{y} u_{y}\right)}{\partial y}=F_{\mathrm{D}, \mathrm{y}}+F_{\mathrm{G}}
\end{array}\right.
$$

where $\bar{\rho}$ is the apparent density of the raindrop phase. $u_{x}$ and $u_{y}$ are the components of the velocity vector of the raindrop phase. $F_{\mathrm{D}, \mathrm{x}}$ and $F_{\mathrm{D}, \mathrm{y}}$ are the components of the air drag vector of the unit mass particle in the raindrop phase. $F_{\mathrm{G}}$ is the resultant force of gravity and air buoyancy of unit mass particle in the raindrop phase. $F_{\mathrm{D}, \mathrm{x}}, F_{\mathrm{D}, \mathrm{y}}$, and $F_{\mathrm{G}}$ are written as follows:

$$
\left\{\begin{array}{l}
F_{\mathrm{D}, \mathrm{x}}=\frac{0.75 \bar{\rho} C_{\mathrm{D}} \operatorname{Re}_{\mathrm{W}} \mu_{\mathrm{a}}\left(v_{x}-u_{x}\right)}{\rho_{\mathrm{W}} \bullet M V D^{2}} \\
F_{\mathrm{D}, \mathrm{y}}=\frac{0.75 \bar{\rho} C_{\mathrm{D}} \operatorname{Re}_{\mathrm{W}} \mu_{a}\left(v_{y}-u_{y}\right)}{\rho_{\mathrm{W}} \bullet M V D^{2}} \\
F_{\mathrm{G}}=\bar{\rho} g\left(1-\frac{\rho_{\mathrm{H}}}{\rho_{\mathrm{W}}}\right)
\end{array}\right.
$$

where $\mu_{a}$ is the viscosity coefficient of the air phase. $v_{x}$ and $v_{y}$ are the components of the velocity vector of the air phase. $g$ is the acceleration of gravity. Referring to ice accretion research [29], the air drag coefficient of the unit raindrop $\left(C_{D}\right)$ is written as follows:

$$
C_{\mathrm{D}}=24\left(1+0.197 \mathrm{Re}_{\mathrm{W}}{ }^{0.63}+2.6 \times 10^{-4} \mathrm{Re}_{\mathrm{W}}{ }^{1.38}\right),
$$

where the Reynolds number parameter $\left(\operatorname{Re}_{\mathrm{W}}\right)$ is

$$
\operatorname{Re}_{\mathrm{W}}=\frac{\rho_{\mathrm{H}} \bullet M V D}{\mu_{a}} \sqrt{\left(v_{x}-u_{x}\right)^{2}+\left(v_{y}-u_{y}\right)^{2}} .
$$

The Governing Equations (5) can be discretized by the finite volume method (FVM) using the body-fitted coordinate system. The discretization of the convection term is adopted using the QUICK (quadratic upwind interpolation of convective kinematics) scheme with a second-order precision [30]. The time term is discretized by the 1st-order implicit scheme. The initial velocity of the raindrop phase can be written as follows:

$$
U_{\infty}=\sqrt{V_{\mathrm{H}}^{2}+V_{\mathrm{a}}^{2}}
$$

where $V_{\mathrm{a}}$ is the relative resultant airflow velocity of the blade airfoil.

2.3. Formation of the Water Film. The thin water film is actually subjected to the inertia forces because it is immersed in the centrifugal field resulting from the rotation of the rotor. Under the action of 3D space and centrifugal loads, the water film might flow to the outer radial direction of the rotor blade in addition to the direction along with the chord-line of the rotor blade. These effects of radial flows and centrifugal loads on aerodynamics, however, are not considered in helicopter engineering design due to the high cost of computing resources and the little significance of engineering application. Thus, radial flows and centrifugal loads are also not considered in our present work in order to quickly understand the influence of rainfall from the perspective of engineering application.

Formation of the water film (FWF) is a complex and key research issue in the rain study. Traditionally, the process of FWF is solved from the following equation referred to in reference [9].

$$
h(i)=h_{0}(i)+\left(\frac{1}{\rho_{\mathrm{w}}}\right) \cdot \dot{\mathrm{m}}_{i} \bullet \Delta t
$$

where $h(i)$ and $\dot{m}_{i}$ are the water film thickness and the mass change rate of the $i^{\text {th }}$ control cell of the water film, respectively. $h_{0}(i)$ is the initial value of $h(i)$, and $\Delta t$ is the simulation time step.

With the increase in the simulation time, solution to the water film thickness tends to be stable theoretically based on the conservation of mass. However, because it is directly affected by $h_{0}$ and $\Delta t$, and $h_{0}$ is artificially designated [9], this traditional method seems to be large affected by numerical fluctuations. Thus, the calculation accuracy seems to be low.

In this section, a novel Direct-FWF method is proposed, which can obtain the water film thickness without iteration in the time history. In this method, the control cells of the water film are set at the first-layer grid of the airfoil wall in the air phase solution domain, and the sequence of control cells could be defined as from the trailing edge of the lower airfoil wall to the trailing edge of the upper airfoil wall. The idea of this method is that when the mass change rate of each control cell reaches to zero, the water film flow reaches equilibrium, and its thickness no longer changes.

Stall in high AOA conditions is considered because of the need of calculation of the aerodynamics in reversed flow region of the rotor in the rain conditions. In high AOA conditions, there may exist an air transition (AT) points and even an air reattachment (AR) points in addition to an air attachment (AA) points. Thus, considering the possible existence of these points (AA, AT, and AR), the process of FWF is analyzed and modeled. Figure 1 shows the sketch of the Direct-FWF method. Note that the AA point is located in the $i_{0}^{\text {th }}$ control cell, AT point is located in the $i_{1}^{\text {th }}$ control cell, and AR point is located in the $i_{2}^{\text {th }}$ control cell. 

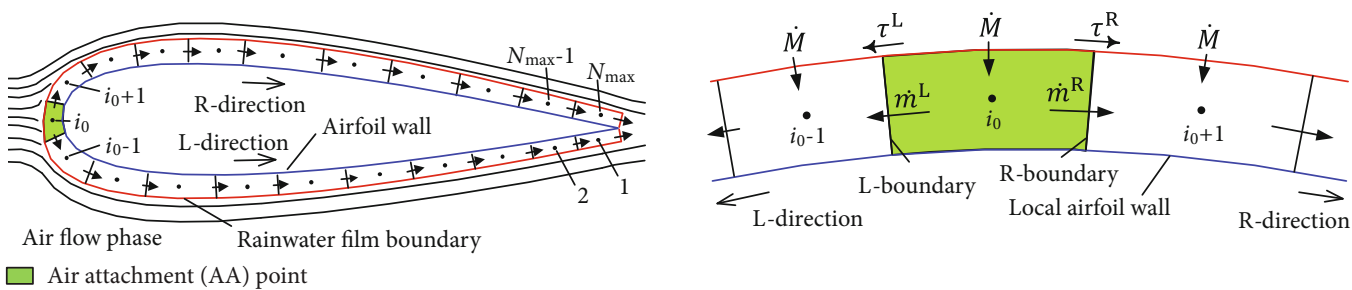

(a)
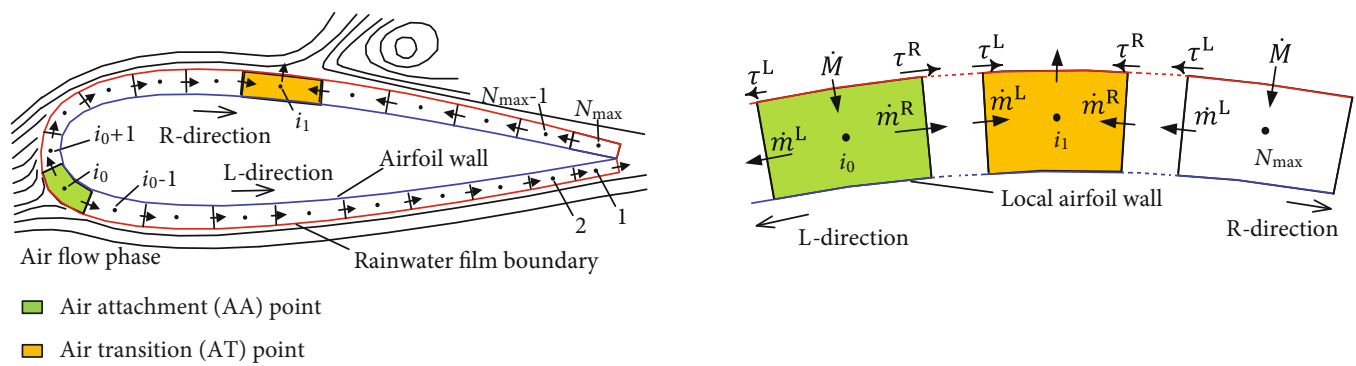

(b)
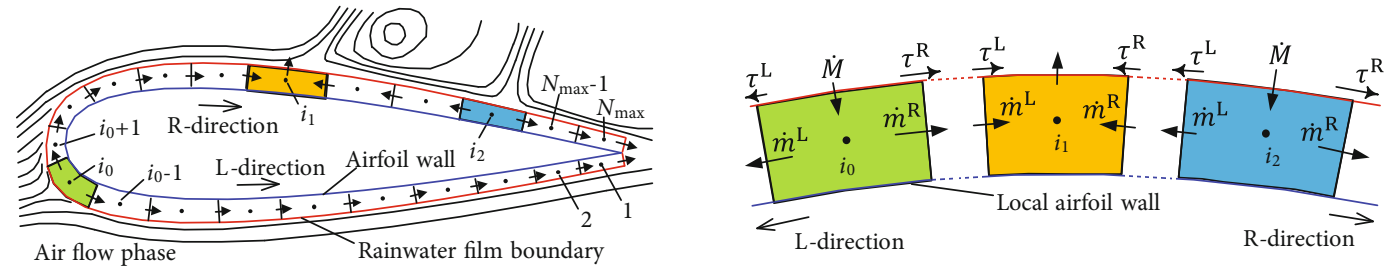

$\square$ Air attachment (AA) point

$\square$ Air transition (AT) point

$\square$ Air reattachment (AR) point

(c)

FIGURE 1: Sketch of the Direct-FWF method with (a) the case of AA point existent, (b) the case of AA and AT points existent, and (c) the case of AA, AT, and AR points existent.

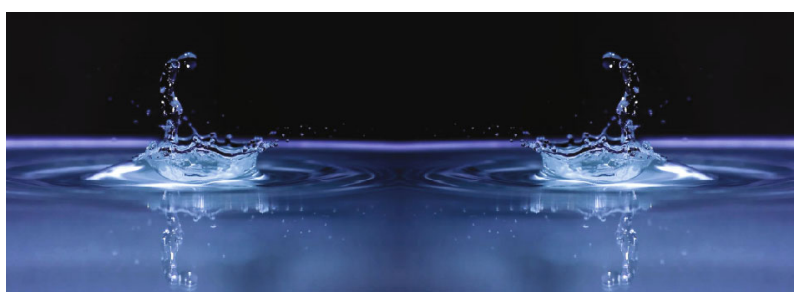

(a)

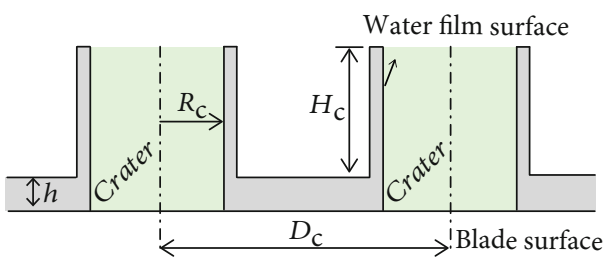

(b)

Figure 2: Sketch of (a) physical phenomenon of the raindrop splash and (b) raindrop splash model.

According to the laminar water film flow assumption, the velocity of the water flow at the wall normal thickness $z_{i}$ of the $i^{\text {th }}$ control cell is written as follows:

$$
u_{i}=\frac{\tau_{i} z_{i}}{\mu_{\mathrm{w}}},\left(0 \leq z_{i} \leq h_{i}\right)
$$

where $\tau_{i}$ is the boundary shear stress between the air phase and water film of the $i^{\text {th }}$ control cell. $\mu_{\mathrm{w}}$ is the viscosity coefficient of water. The mass change rate of an arbitrary $X$ -boundary (i.e., L-boundary or R-boundary) of the $i^{\text {th }}$ control cell is

$$
\dot{m}_{i}^{\mathrm{X}}=\int_{0}^{h_{i}^{\mathrm{X}}} \rho_{\mathrm{w}} \bullet u_{i}^{X} \cdot \mathrm{d} z_{i}=\frac{0.5 \rho_{\mathrm{w}} \tau_{i}^{\mathrm{X}}\left(h_{i}^{\mathrm{X}}\right)^{2}}{\mu_{\mathrm{w}}} .
$$




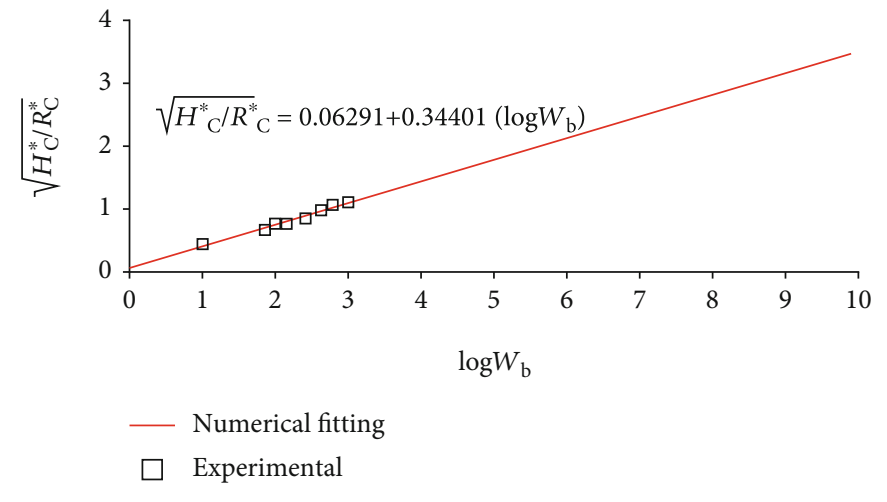

(a)

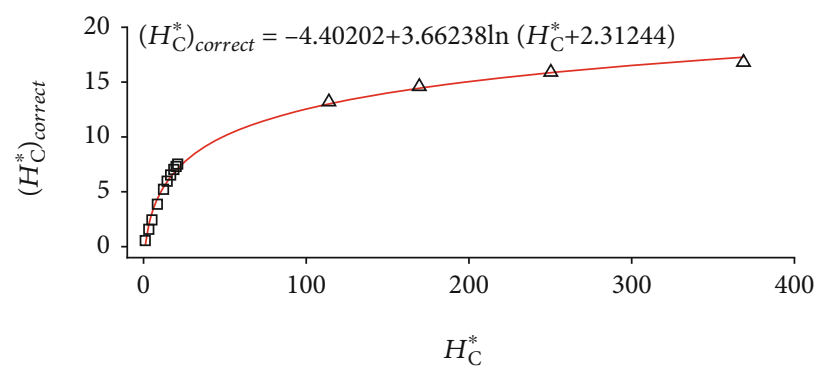

_ Numerical fitting

$\square$ Experimental

$\triangle$ Reference data

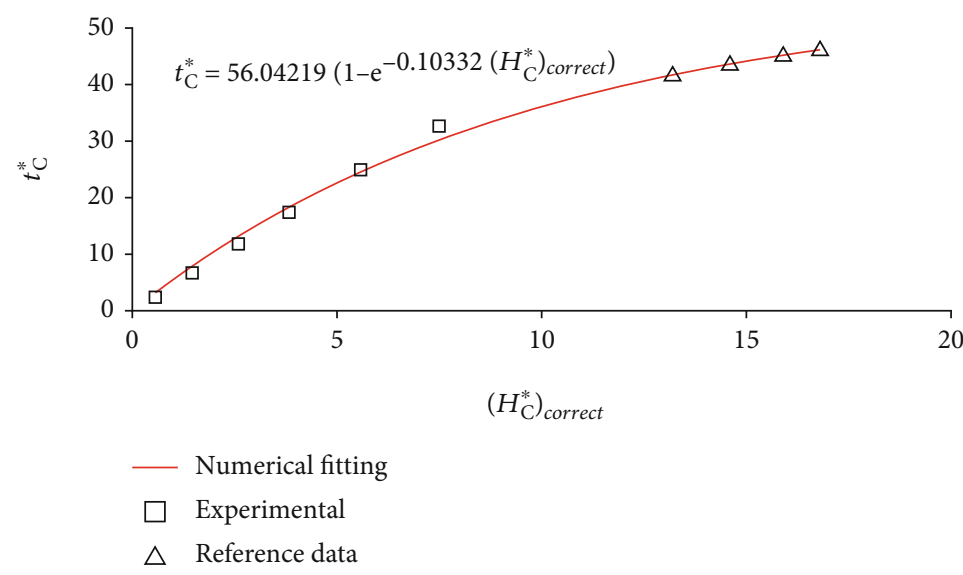

(c)

FIgURE 3: Numerical fitting of (a) $\sqrt{H_{\mathrm{C}}^{*} / R_{\mathrm{C}}^{*}}-\log W_{\mathrm{b}}$, (b) $\left(H_{\mathrm{C}}^{*}\right)_{\text {correct }}-H_{\mathrm{C}}^{*}$, and (c) $t_{\mathrm{c}}^{*}-\left(H_{\mathrm{C}}^{*}\right)_{\text {correct }}$.
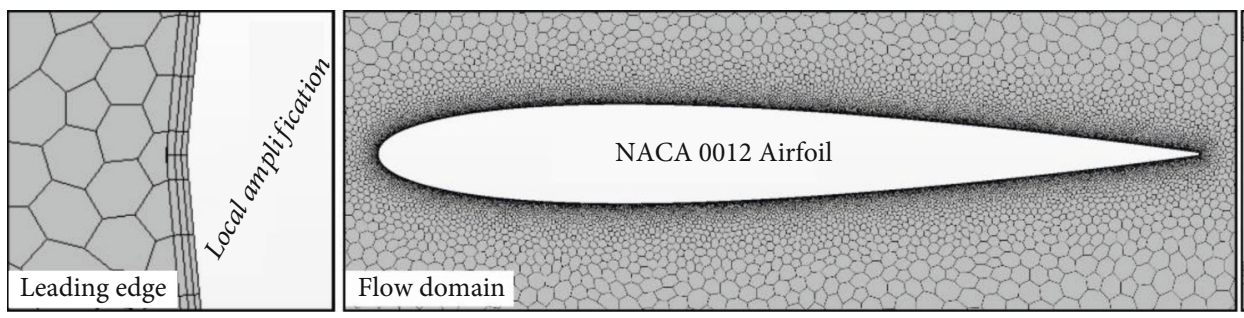

(a)
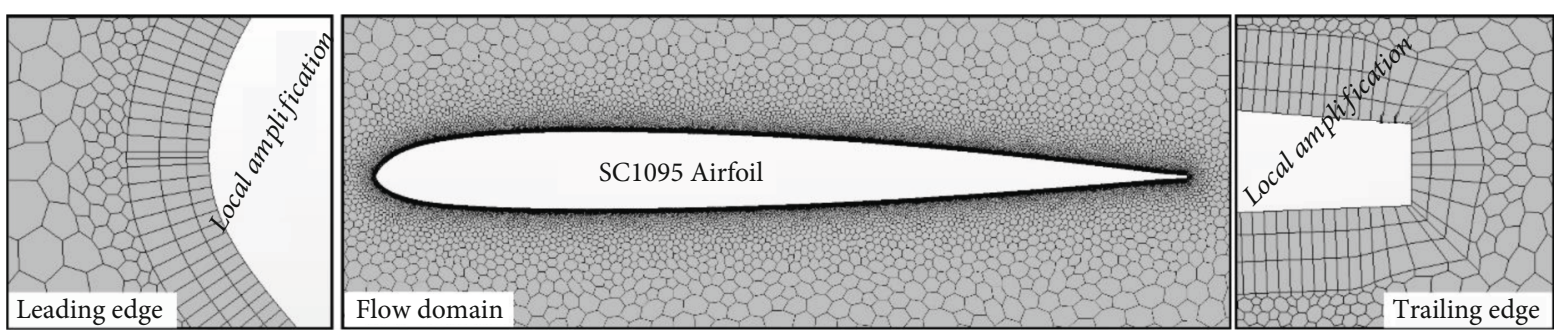

(b)

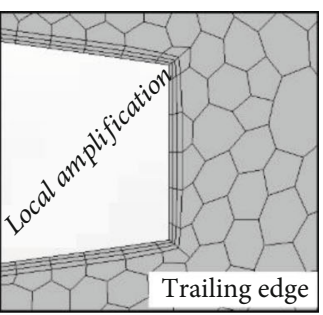

Trailing edge

railing edge

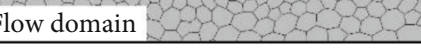

FIGURE 4: The mesh view of the flow domains for (a) validation case of NACA 0012 airfoil and (b) application case of SC1095 airfoil. 
SC1095 Airfoil

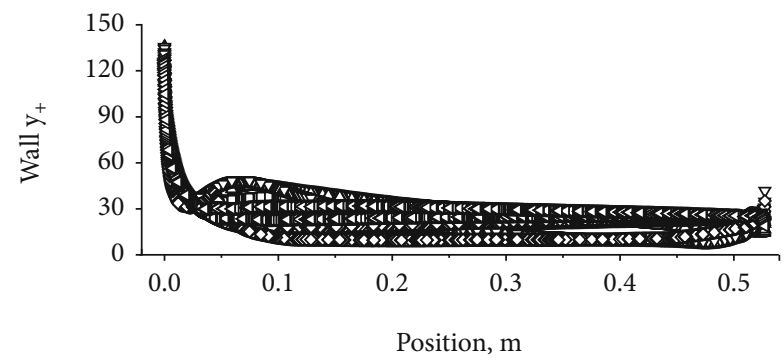

(a)

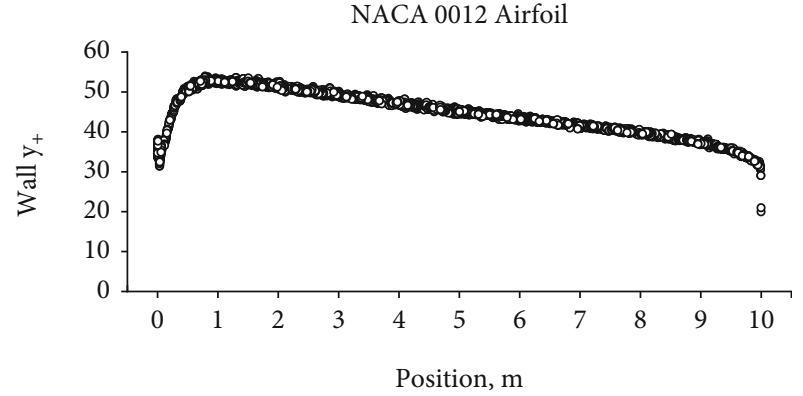

(b)

FIgURE 5: Wall $y+$ plots for (a) validation case of NACA 0012 airfoil and (b) application case of SC1095 airfoil.

TABLE 1: Calculation settings.

\begin{tabular}{lcccc}
\hline Airfoil & Chord length $(\mathrm{m})$ & Velocity $(\mathrm{m} / \mathrm{sec})$ & AOA $(\mathrm{deg})$ & Rain rate $(\mathrm{mm} / \mathrm{h})$ \\
\hline SC1095 & 0.5273 & 34.0 & {$[-26,26]$} & 1500 \\
NACA 0012 & 10.0 & 65.0 & 0 & $100,200,500,1000$, and 2000 \\
\hline
\end{tabular}

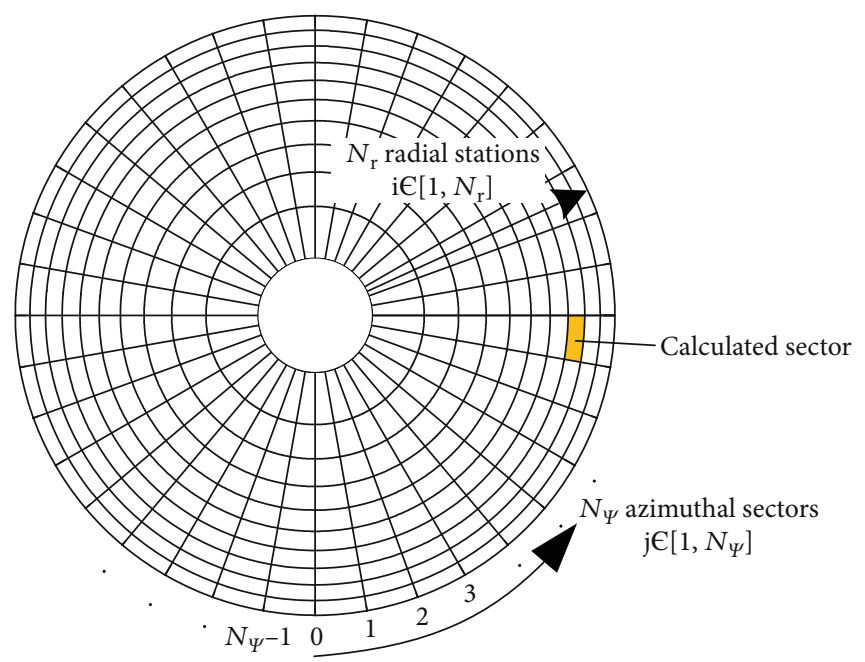

FIGURE 6: Sketch of the discretization analysis method.

Local raindrop impinging mass change rate of the $i^{\text {th }}$ control cell is

$$
\dot{M}_{i}=L W C \cdot \beta_{i} \cdot U_{\infty} \bullet S_{i}
$$

where $S_{i}$ is the length of the local airfoil wall occupying by the $i^{\text {th }}$ control cell. $\beta_{i}$ is the local raindrop collection efficiency of the $i^{\text {th }}$ control cell, as follows:

$$
\beta_{i}=\frac{\bar{\rho}_{i} \bullet \nu_{\perp i}}{L W C \cdot U_{\infty}}
$$

where $v_{\perp i}$ is the normal velocity of the raindrop impinging on the airfoil wall of the $i^{\text {th }}$ control cell.
The water flow balance equation in the $i_{0}^{\text {th }}$ and $i_{2}^{\text {th }}$ control cells can be deduced as follows:

$$
\dot{M}_{i}=\dot{m}_{i}^{\mathrm{L}}+\dot{m}_{i}^{\mathrm{R}},\left(i=i_{0} \text { or } i=i_{2}\right) .
$$

Suppose that the $i_{0}^{\text {th }}$ and $i_{2}^{\text {th }}$ control cells are rectangles, $h_{i_{0}}$ and $h_{i_{2}}$ can be deduced as follows:

$$
h_{i}=h_{i}^{\mathrm{L}}=h_{i}^{\mathrm{R}}=\sqrt{\frac{2 \dot{M}_{i} \cdot \mu_{\mathrm{w}}}{\rho_{\mathrm{w}}\left(\left|\tau_{i}^{\mathrm{L}}\right|+\left|\tau_{i}^{\mathrm{R}}\right|\right)}},\left(i=i_{0} \text { or } i=i_{2}\right) .
$$

Because the airflow around the airfoil wall is firstly divided into two air streams at AA point, the water in the control cells of the L-direction of the $i_{0}^{\text {th }}$ control cell flows to the L-direction. In addition, if AR point is existent, AT 


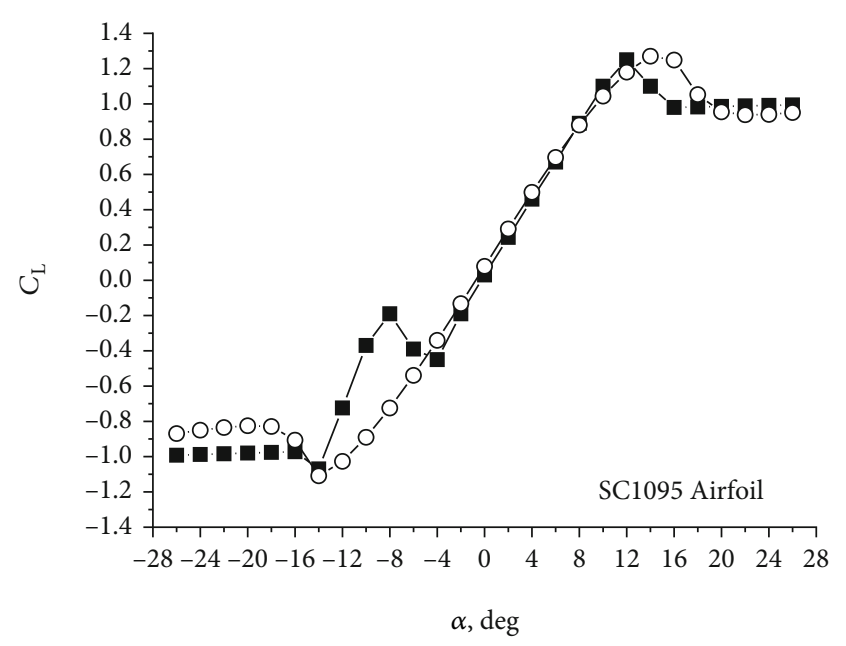

(a)

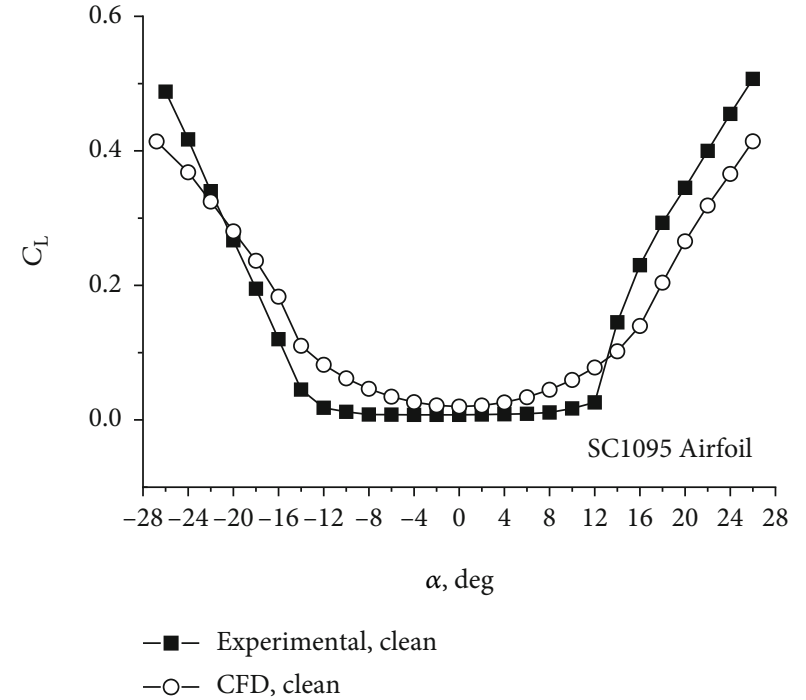

(b)

FiguRE 7: (a) Lift coefficient and (b) drag coefficient of SC1095 clean airfoil.

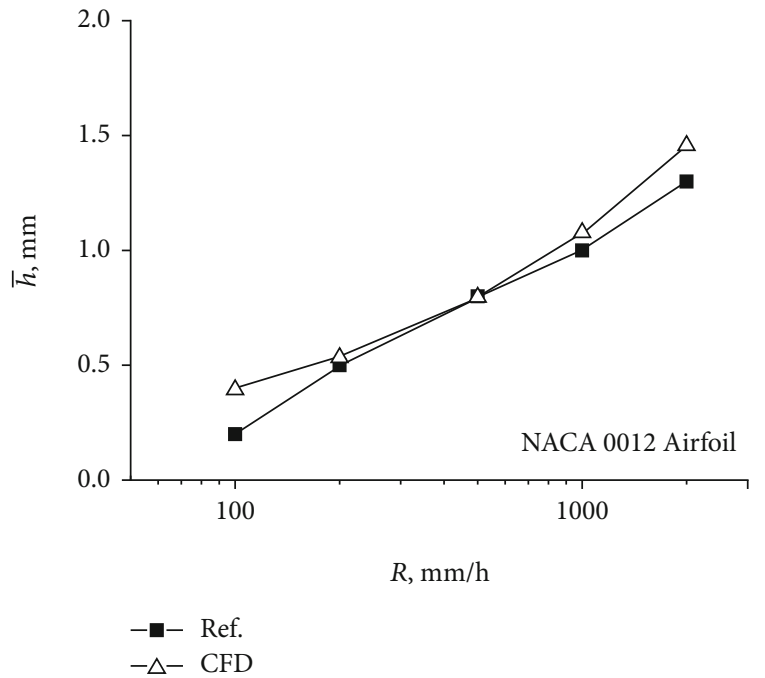

FIGURE 8: The averaged water film thickness $(\bar{h})$ of NACA 0012 airfoil in different rain rates $(R)$.

point exists, and the water in the control cells of the Ldirection of the $i_{2}^{\text {th }}$ control cell also flows to the L-direction due to the adverse pressure gradient. The corresponding water flow balance equation is written as follows:

$$
\dot{m}_{i}^{\mathrm{L}}=\dot{M}_{i}+\dot{m}_{i}^{\mathrm{R}},\left(1 \leq i<i_{0} \text { or } i_{1}<i<i_{2}\right) .
$$

As for the water in the control cells of the R-direction of the $i_{0}^{\text {th }}$ control cell, it flows in the R-direction until the existence of AT point (i.e., stall or approaching stall circumstance). As seen Figure 1(c), if AR point is existent, the water in control cells of the R-direction of the $i_{2}^{\text {th }}$ control cell also flows to the R-direction. The corresponding water flow balance equation is written as follows:

$$
\dot{m}_{i}^{\mathrm{R}}=\dot{M}_{i}+\dot{m}_{i}^{\mathrm{L}},\left(i_{0}<i<i_{1} \text { or } i_{2}<i \leq N_{\max }\right)
$$

If AT point is not existent, AR point does not exist, and the applicable condition of Equation (18) can be changed into $i_{0}<i \leq N_{\max }$.

In the simulation, $h_{i}$ can be directly obtained by combining with Equations (12), (13), (17), and (18) once $h_{i_{0}}$ and the possible $h_{i_{2}}$ are firstly solved.

2.4. Water Film Roughness. After the water film forms on the blade surface, the raindrops will continue to strike the water film surface, causing the water film surface to produce craters. It is the so-called raindrop splash effect [28]. It makes the water film surface to be not smooth. In addition, surface waves will generate on the water film surface due to the stress of airflow. Both the raindrop splash effect and surface waves will make the water film surface rough affecting the airflow field around the blade airfoil and degrading the rotor aerodynamic performance.

The equivalent water film roughness is developed as follows:

$$
k_{\mathrm{S}}=\left\|\left[k_{\mathrm{S}, \mathrm{C}}, k_{\mathrm{S}, \mathrm{W}}\right]\right\|
$$

where $k_{\mathrm{S}, \mathrm{C}}$ is the roughness due to craters generated by the raindrop splash effect and $k_{\mathrm{S}, \mathrm{W}}$ is the roughness due to surface waves of the water film.

In general, $k_{\mathrm{S}, \mathrm{W}}$ is proportionate to the average height of the water film [6], as follows:

$$
k_{\mathrm{S}, \mathrm{W}}=1.5 \bar{h}
$$




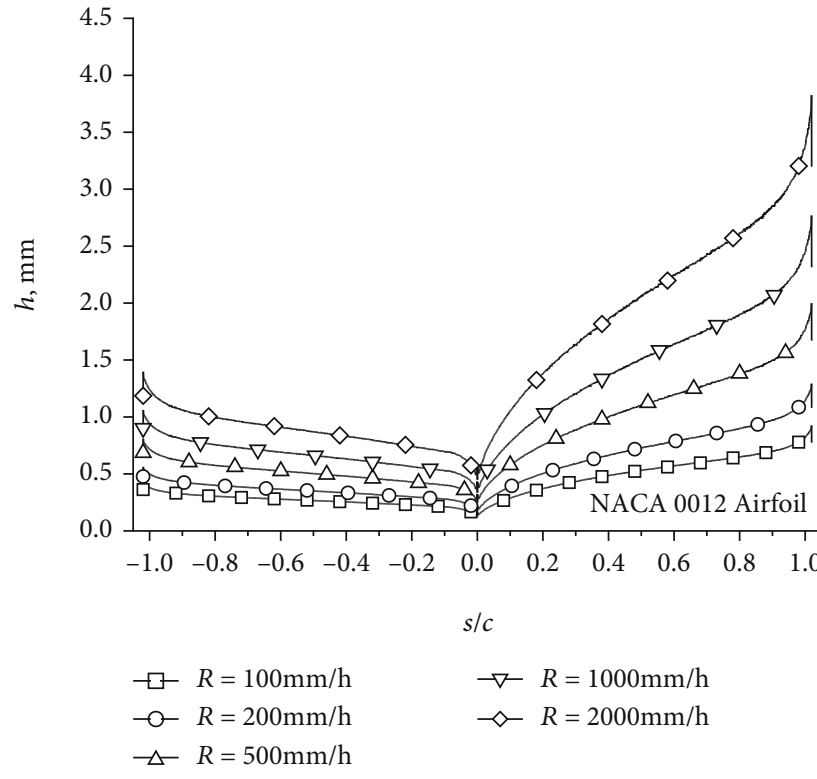

(a)

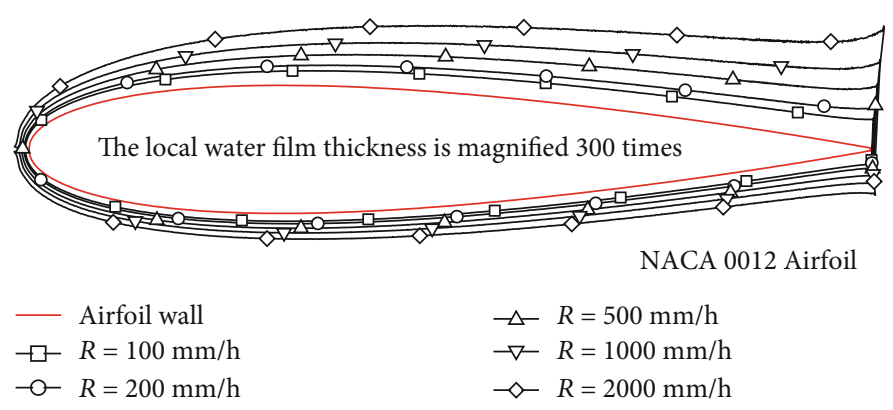

(b)

Figure 9: (a) Coordinate view and (b) geometrical view of local water film thickness of NACA0012 airfoil in different rain rates $(R)$.

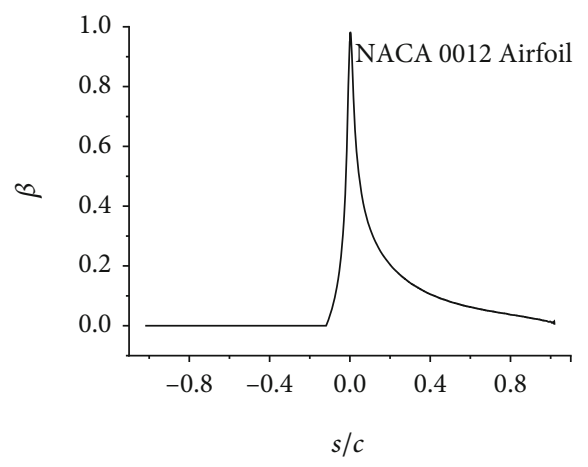

FIGURE 10: Local raindrop collection efficiency $(\beta)$ of NACA 0012 airfoil.

According to reference [31], the equivalent sand-grain roughness is adopted to simulate $k_{\mathrm{S}, \mathrm{C}}$, as follows:

$$
\begin{gathered}
k_{\mathrm{S}, \mathrm{C}}=\left\{\begin{array}{l}
0.0164 \Lambda^{3.7} \bar{H}_{\mathrm{C}},(\Lambda \leq 4.93) \\
139 \Lambda^{-1.9} \bar{H}_{\mathrm{C}},(\Lambda>4.93),
\end{array}\right. \\
\Lambda=\left(\frac{\bar{D}_{\mathrm{C}}}{\bar{H}_{\mathrm{C}}}\right) \cdot C^{-\frac{4}{3}},
\end{gathered}
$$

where $C$ is an empirical coefficient and $\bar{D}_{\mathrm{C}}$ and $\bar{H}_{\mathrm{C}}$ are obtained by solution to the raindrop splash effect.

2.5. Raindrop Splash Model. Figure 2 shows the physical phenomena of the raindrop splash and the analytical model. Note that $R_{\mathrm{C}}$ and $H_{\mathrm{C}}$ are the maximum radius and maximum height of crater in the process of crater formation, respectively. $D_{\mathrm{C}}$ is the crater spacing.
Theoretically, the process of crater formation due to the collision of raindrops and water film is just the process of water film morphology change. According to the principle of energy balance, the total energy of a raindrop before collision $\left(E_{\mathrm{D}}\right)$ is equal to the surface energy required for the change of water film morphology of a cylindrical crater $\left(E_{\mathrm{F}}\right.$ ). It can be written as follows:

$$
E_{\mathrm{D}}=E_{\mathrm{F}},
$$

where $E_{\mathrm{D}}$ and $E_{\mathrm{F}}$ are

$$
\left\{\begin{array}{l}
E_{\mathrm{D}}=0.5 m_{\mathrm{D}} U^{2}+0.5 m_{\mathrm{D}} g D+\pi D^{2} \sigma_{\mathrm{W}} \\
E_{\mathrm{F}}=2 \pi R_{\mathrm{C}}\left(h+2 H_{\mathrm{C}}\right) \sigma_{\mathrm{W}},
\end{array}\right.
$$

where $m_{\mathrm{D}}$ is the raindrop mass. $U$ is the velocity of the raindrop before collision. $\sigma_{\mathrm{W}}$ is the surface tension coefficient of the raindrop.

Then, the nondimensional $H_{\mathrm{C}}$ can be deduced as follows:

$$
H_{\mathrm{C}}^{*}=\frac{1+6 W_{\mathrm{b}}^{-1}+2 F_{\mathrm{N}}^{-1}-3 W_{\mathrm{b}}^{-1} h^{*} R_{\mathrm{C}}^{*}}{6 W_{\mathrm{b}}^{-1} R_{\mathrm{C}}^{*}}
$$

where $W_{\mathrm{b}}$ is the Weber number that indicates the ratio of inertial force to surface tension force and $F_{\mathrm{N}}$ is the Froude number that indicates the ratio of inertial force to gravitational force.

$$
\begin{gathered}
W_{\mathrm{b}}=0.5 \cdot \rho_{\mathrm{w}} \cdot M V D \cdot \frac{v_{\perp}^{2}}{\sigma_{\mathrm{W}}}, \\
F_{\mathrm{N}}=2 \cdot \frac{v_{\perp}^{2}}{g \cdot M V D},
\end{gathered}
$$




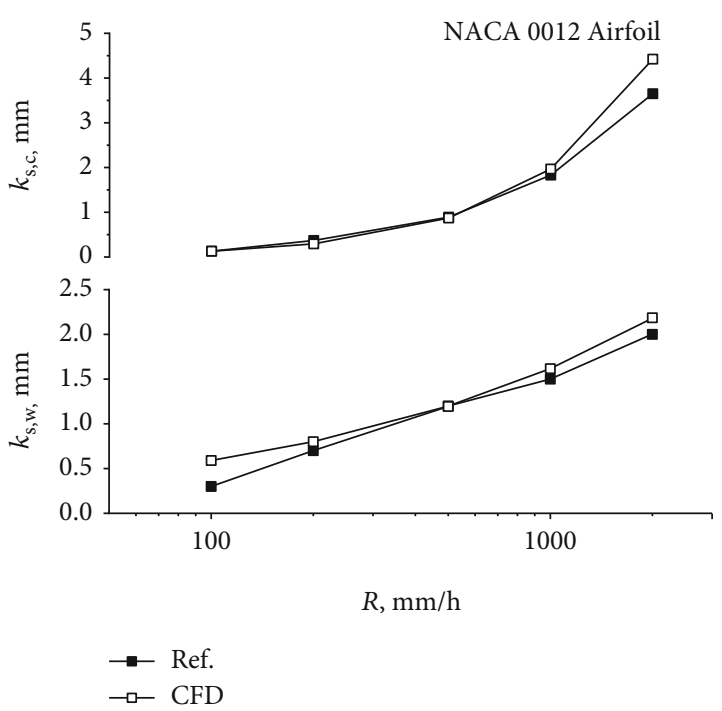

FIGURE 11: Water film roughness of NACA0012 airfoil in different rain rates $(R)$.

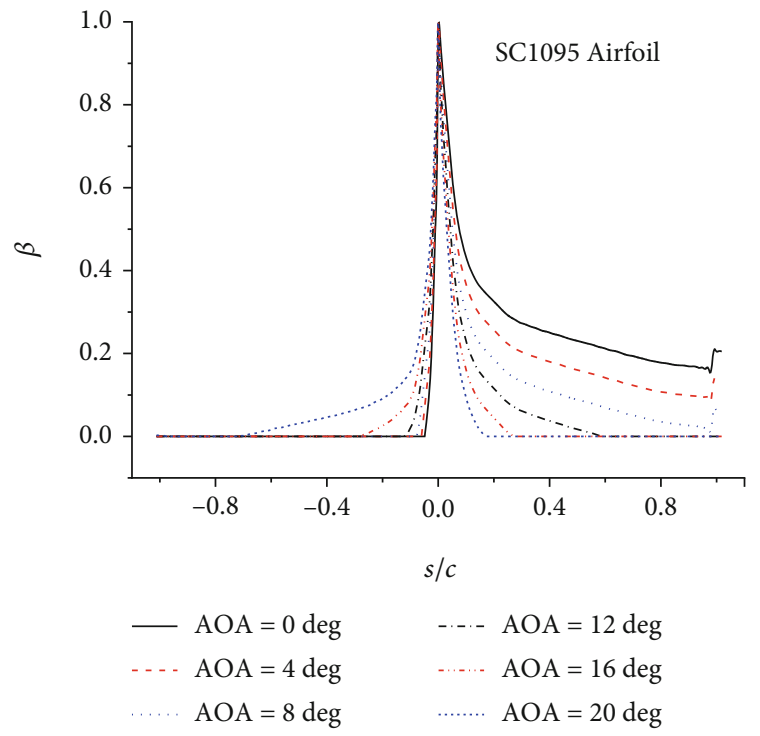

FIgURE 12: The local raindrop collection efficiency $(\beta)$ of SC1095 airfoil in different AOAs.

$$
H_{C}^{*}=2 H_{C} / D ; h^{*}=2 h / D ; R_{C}^{*}=2 R_{C} / D
$$

Experiments [32] indicated that $\sqrt{H_{\mathrm{C}}^{*} / R_{\mathrm{C}}^{*}}$ and $\log W_{\mathrm{b}}$ are in a nearly linear relationship, as shown in Figure 3(a). In this article, this relationship is written using the linear fitting technique, as follows:

$$
\sqrt{H_{\mathrm{C}}^{*} / R_{\mathrm{C}}^{*}}=0.06291+0.34401\left(\log W_{\mathrm{b}}\right) .
$$

Combined with Equations (25) and (29), the theoretical $H_{\mathrm{C}}^{*}$ is solved. As shown in Figure 3(b), when we consider the actual energy dissipation and the potential energy difference, by using the experimental data [32] and reference data
[27], the correction of $H_{\mathrm{C}}^{*}$ is

$$
\left(H_{\mathrm{C}}^{*}\right)_{\text {correct }}=-4.40202+3.66238 \ln \left(H_{\mathrm{C}}^{*}+2.31244\right) \text {. }
$$

The average height of the crater due to raindrops with diameter $D$ can be estimated as a half of $\left(H_{\mathrm{C}}^{*}\right)_{\text {correct }}$.

$$
H_{\mathrm{C}}(D)=0.5 \bullet\left(H_{\mathrm{C}}^{*}\right)_{\text {correct }} \bullet D / 2
$$

By using the classical Marshall \& Palmer's size distribution of raindrops, the equivalent average height of the whole craters due to raindrops is deduced as follows:

$$
\bar{H}_{\mathrm{C}}=\frac{\int_{0}^{\infty} H_{\mathrm{C}}(D) \cdot N(D) \mathrm{d} D}{\int_{0}^{\infty} N(D) \mathrm{d} D}=\frac{\left(H_{\mathrm{C}}^{*}\right)_{\text {correct }}}{4 I} .
$$

According to experiments [32], it can be assumed that the existence time of a crater $(\Delta t)$ is twice as long as the formation time of the crater $\left(t_{c}\right)$. During the time $(\Delta t)$ of the continuous rainfall, the total number of craters $\left(N_{\mathrm{D}}\right)$ formed by raindrops with diameter $D$ in the unit area of the blade airfoil wall can be deduced as follows:

$$
N_{\mathrm{D}}=N(D) \cdot U_{\mathrm{c}} \bullet \Delta t \bullet \beta=N(D) \cdot D \bullet t_{\mathrm{c}}^{*} \bullet \beta / 1000,
$$

where $t_{\mathrm{c}}^{*}=2000 \bullet U_{\infty} \bullet(0.5 \Delta t) / D$. As shown in Figure 3(c), based on the numerical fitting technique, by using the experimental data [32] and reference data [27], $t_{c}^{*}$ is written as follows:

$$
t_{\mathrm{c}}^{*}=56.04219\left(1-e^{-0.10332\left(H_{\mathrm{C}}^{*}\right)_{\text {correct }}}\right) .
$$

Because the classical Marshall \& Palmer's size distribution of raindrops [26] is adopted to simulate rainfall, the total number of craters $(N)$ formed by rainfall in the unit area of the blade airfoil wall can be deduced as follows:

$$
N=\int_{0}^{\infty} N_{\mathrm{D}} \mathrm{d} D=\frac{N_{0} t_{\mathrm{c}}^{*} \beta}{1000 I^{2}}
$$

The average value of $D_{C}$ in the unit area of the blade airfoil wall can be estimated as follows:

$$
\bar{D}_{\mathrm{C}}=\frac{1000}{\sqrt{N}}=3.162 \times 10^{4} \cdot \frac{I}{\sqrt{N_{0} t_{c}^{*} \beta}} .
$$

Equations (32) and (36) can be used to solve $k_{\mathrm{S}, \mathrm{C}}$ using Equations (21) and (22).

2.6. Mesh Generation and Calculation Settings. CFD simulations are conducted, including the case of NACA 0012 airfoil with $10 \mathrm{~m}$ chord length [6] and the case of SC1095 airfoil used in the full-scale rotor of UH-60A helicopter [33]. STAR-CCM+ is used to divide the grid, while the unstructured/structured hybrid grid is used for the flow domain of the airfoils. Figure 4 shows the parts of the mesh view of the flow domain. A three-layer structured grid along the 


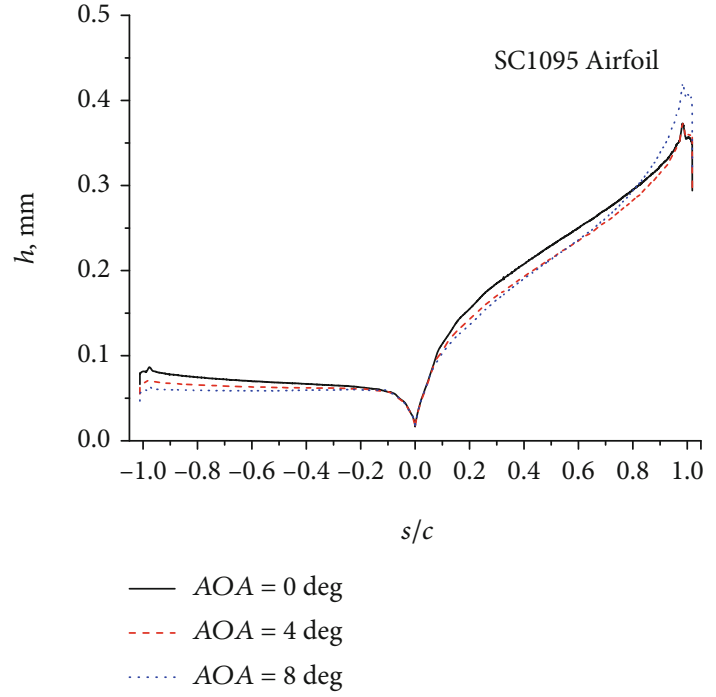

(a)

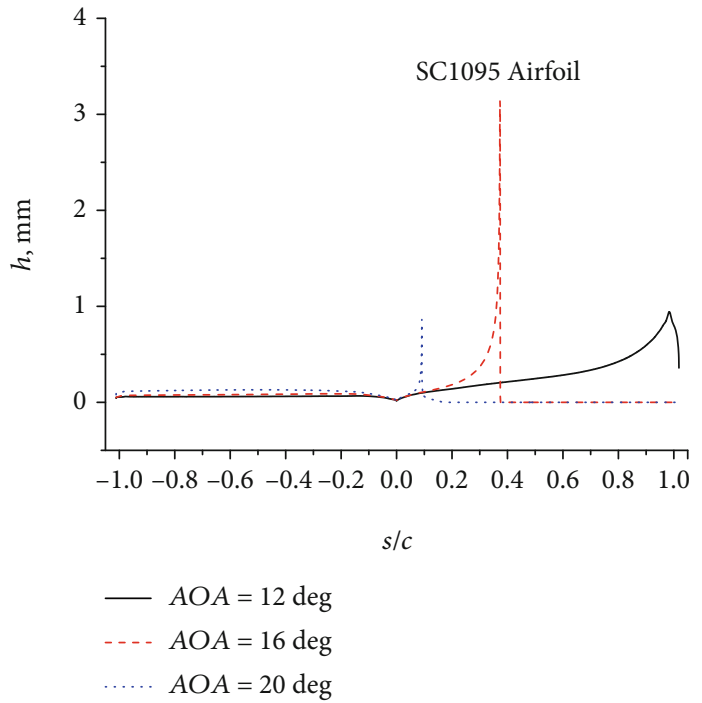

(b)

FIGURE 13: Coordinate view of the local water film thickness of SC1095 airfoil in (a) AOAs from 0 deg to 8 deg and (b) AOAs from 12 deg to 20 deg.
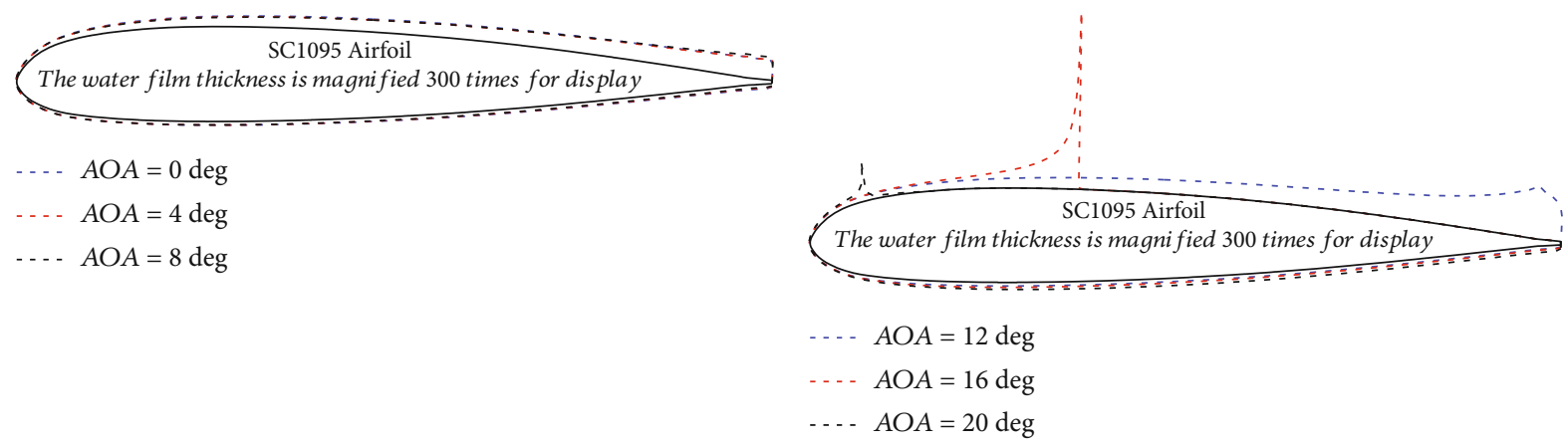

(a)

(b)

FIGURE 14: Geometrical view of the local water film thickness of SC1095 airfoil in AOAs (a) from 0 deg to 8 deg and (b) from 12 deg to 20 deg.

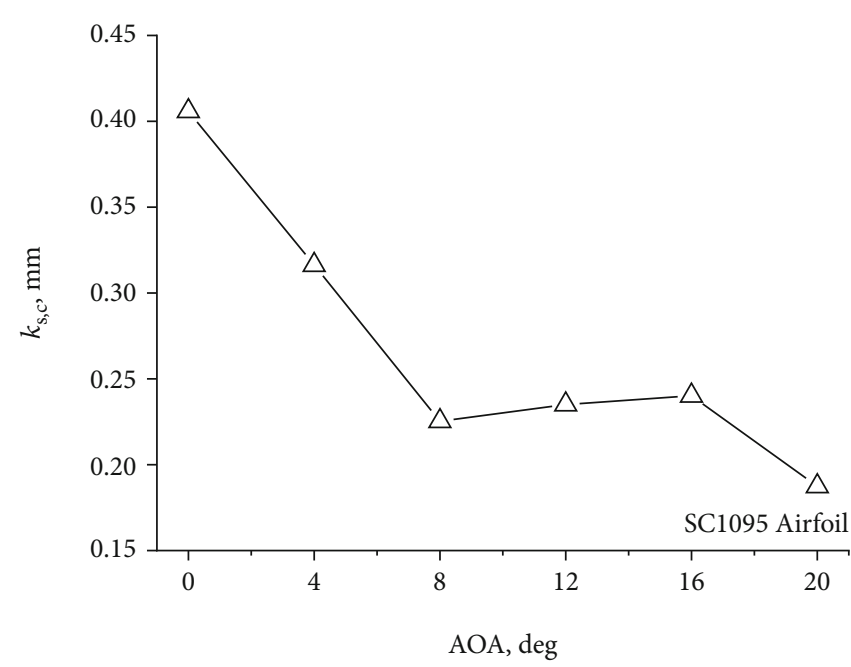

(a)

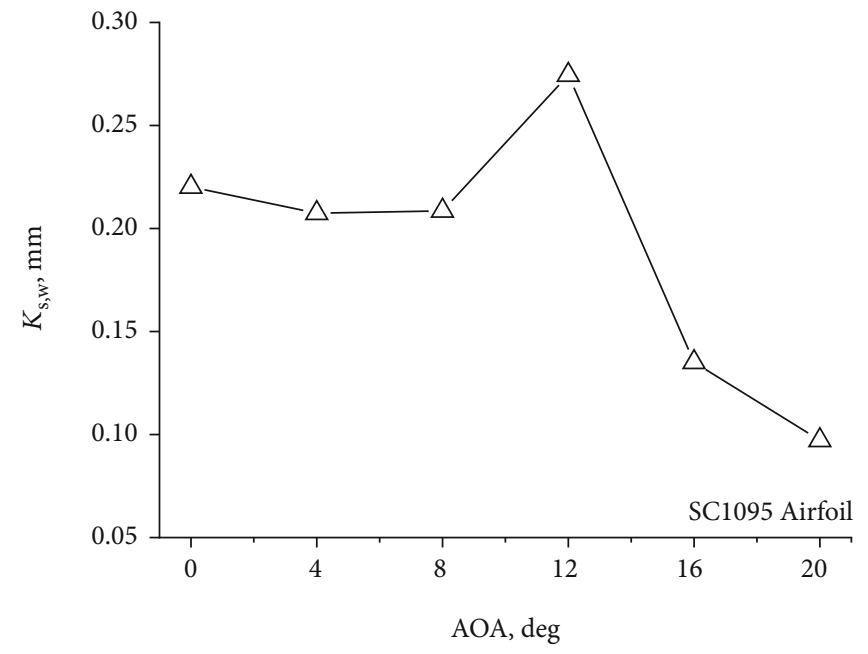

(b)

FIgURE 15: (a) Roughness due to craters and (b) roughness due to water waves of SC1095 airfoil in different AOAs. 
TABLe 2: CFD simulation data of the SC1095 blade airfoil in rain condition.

\begin{tabular}{lcccccc}
\hline AOA & \multicolumn{3}{c}{ Lift coefficient } & \multicolumn{3}{c}{ Drag coefficient } \\
(deg) & Clean & Rain & Del & Clean & Rain & Del \\
\hline 0 & 0.07901 & 0.07656 & $-3.10 \%$ & 0.01988 & 0.02515 & $26.51 \%$ \\
4 & 0.49842 & 0.48888 & $-1.91 \%$ & 0.02597 & 0.03124 & $20.29 \%$ \\
8 & 0.87999 & 0.86370 & $-1.85 \%$ & 0.04479 & 0.05028 & $12.26 \%$ \\
12 & 1.17984 & 1.14808 & $-2.69 \%$ & 0.07792 & 0.08512 & $9.24 \%$ \\
16 & 1.24857 & 1.08936 & $-12.75 \%$ & 0.13959 & 0.16701 & $19.64 \%$ \\
20 & 0.95476 & 0.90432 & $-5.28 \%$ & 0.26550 & 0.28547 & $7.52 \%$ \\
\hline
\end{tabular}

TABLE 3: Averaged lift-to-drag ratio of the UH-60A helicopter rotor disk.

\begin{tabular}{lccc}
\hline$D X$ (knots) & Clean & Rain & Del \\
\hline 0 & 73.25 & 53.91 & $-26.39 \%$ \\
40 & 68.26 & 50.62 & $-25.85 \%$ \\
80 & 65.14 & 48.72 & $-25.21 \%$ \\
120 & 62.78 & 47.70 & $-24.02 \%$ \\
160 & 52.19 & 40.11 & $-23.14 \%$ \\
\hline
\end{tabular}

normal direction of the airfoil wall is generated. In which, the height of the first cell adjacent to the airfoil wall is $0.5 \mathrm{~mm}$ corresponding to a maximum $y+$ of approximately small than 150 for the whole calculation settings (see Figure 5). Table 1 shows the calculation settings. In addition, the grid growth rate is 1.2 , and the minimum surface relative size of the airfoil wall is $0.025 \%$. The grid numbers of the flow domain of SC1095 and NACA 0012 airfoils are 116133 and 120216, respectively.

In Table 1, the calculation settings of AOAs from -26 deg to 26 deg with 2 deg apart are used for the case of SC1095 airfoil due to the operational condition of the large AOA of the helicopter rotor blade. The calculation settings of rain rate of $100,200,500,1000$, and $2000 \mathrm{~mm} / \mathrm{h}$ are used for the case of NACA 0012 airfoil.

2.7. Discretization Analysis Method. The rotor averaging method referred to in our icing studies [34-36] was adopted in order to develop a discretization analysis method of the prediction of the helicopter rotor performance in the rain conditions. According to this method, the rotor disk was divided into $N_{r} \times N_{\psi}$ calculated sectors, with $N_{r}$ radial stations for each of $N_{\psi}$ azimuthal sectors. After analyzing the rotor blade airfoil aerodynamics in the rain conditions in each calculated sector and synthesizing all sectors, the rotor performance degradation can be developed. Figure 6 shows the sketch of the discretization analysis method.

In detail, the lift/drag coefficient of the two-dimensional blade airfoil in the rain conditions in each calculated sector can be expressed as follows:

$$
C_{\mathrm{L}}^{\text {Rain }}=\left(1+\frac{\Delta C_{\mathrm{L}}}{C_{\mathrm{L}}}\right) C_{\mathrm{L}}^{\text {Clean }}
$$

$$
C_{\mathrm{D}}^{\text {Rain }}=\left(1+\frac{\Delta C_{\mathrm{D}}}{C_{\mathrm{D}}}\right) C_{\mathrm{D}}^{\text {Clean }},
$$

where $C_{\mathrm{L}}^{\text {Clean }}$ and $C_{\mathrm{D}}^{\text {Clean }}$ are the lift and drag coefficients of the clean blade airfoil, respectively. In the present study, these come from the wind tunnel test data onto the airfoil. The relative coefficient increments $\Delta C_{\mathrm{L}} / C_{\mathrm{L}}$ and $\Delta C_{\mathrm{D}} / C_{\mathrm{D}}$, which can be obtained by solving the air-raindrop coupling flow field of the two-dimensional rotor blade airfoil in each calculated sector, are written, as follows:

$$
\begin{gathered}
\frac{\Delta C_{\mathrm{L}}}{C_{\mathrm{L}}}=\frac{C_{\mathrm{L}, \mathrm{CFD}}^{\text {Rain }}-C_{\mathrm{L}, \mathrm{CFD}}^{\text {Clean }}}{C_{\mathrm{L}, \mathrm{CFD}}^{\text {Clean }}}, \\
\frac{\Delta C_{\mathrm{D}}}{C_{\mathrm{D}}}=\frac{C_{\mathrm{D}, \mathrm{CFD}}^{\text {Rain }}-C_{\mathrm{D}, \mathrm{CFD}}^{\text {Clean }}}{C_{\mathrm{D}, \mathrm{CFD}}^{\text {Clean }}},
\end{gathered}
$$

where $C_{\mathrm{L}, \mathrm{CFD}}^{\text {Clean }}$ and $C_{\mathrm{D}, \mathrm{CFD}}^{\mathrm{Clean}}$ can be directly derived from the airflow field. $C_{\mathrm{L}, \mathrm{CFD}}^{\text {Rain }}$ and $C_{\mathrm{D}, \mathrm{CFD}}^{\text {Rain }}$ are derived from the updated airflow field after the water film forms on the blade airfoil.

\section{Results and Discussion}

3.1. Validation Case. In our present work, we have not obtained any actual rain test data related to helicopter rotor blade in order to validate our CFD-based method. Thus, NACA0012 airfoil with the chord of $10 \mathrm{~m}$ at $65 \mathrm{~m} / \mathrm{s}$ [6] is independently used to validate our CFD simulation of the raindrop phase, and SC1095 airfoil with the chord of about $0.5 \mathrm{~m}$ at $34 \mathrm{~m} / \mathrm{s}$ [33], that is UH-60A helicopter rotor blade airfoil, is independently used to validate our CFD simulation of the air phase. According to formula (8), the Reynolds number of the raindrop phase is independent of the airfoil chord. Thus, a different chord length of airfoil does not affect the Reynolds number of the raindrop phase, not leading to deviation from the results of the raindrop phase. Thus, the validation case of NACA 0012 is reasonable although its chord length is about 20 times larger than the simulation case of UH-60A helicopter. By comparing with the experimental data onto the air phase and the raindrop phase flow, respectively, our CFD-based method can be validated.

Validation of the air phase is conducted using the clean SC1095 blade airfoil. Lift coefficient $\left(C_{\mathrm{L}}\right)$ and drag coefficient $\left(C_{\mathrm{D}}\right)$ of the airfoil are numerically obtained (Figure 7$)$. Compared with the experimental data [33], the CFD simulations show good results related to $C_{\mathrm{L}}$ and $C_{\mathrm{D}}$, except for some discrepancies in $C_{\mathrm{L}}$ at some of the AOAs (-8 deg, $-10 \mathrm{deg}$, and $-12 \mathrm{deg}$ ) probably due to the difference between the S-A turbulence model and actual flow around the blade airfoil.

Validation of the raindrop phase flow is validated using the NACA 0012 airfoil. Figure 8 shows the averaged water film thickness $(\bar{h})$ of the airfoil in different rain rates. It can be concluded that the CFD results are in good agreement with the reference data [27]. In detail, Figure 9 shows the local water film thickness $(h)$ of the airfoil in different rain rates, and Figure 10 shows the local raindrop collection efficiency $(\beta)$ of the airfoil. Some of the conclusions can be drawn as follows: 


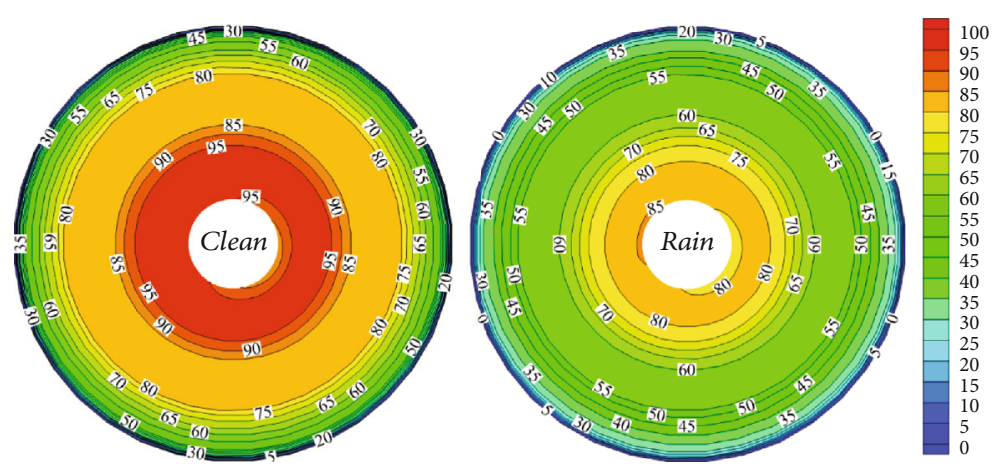

(a)

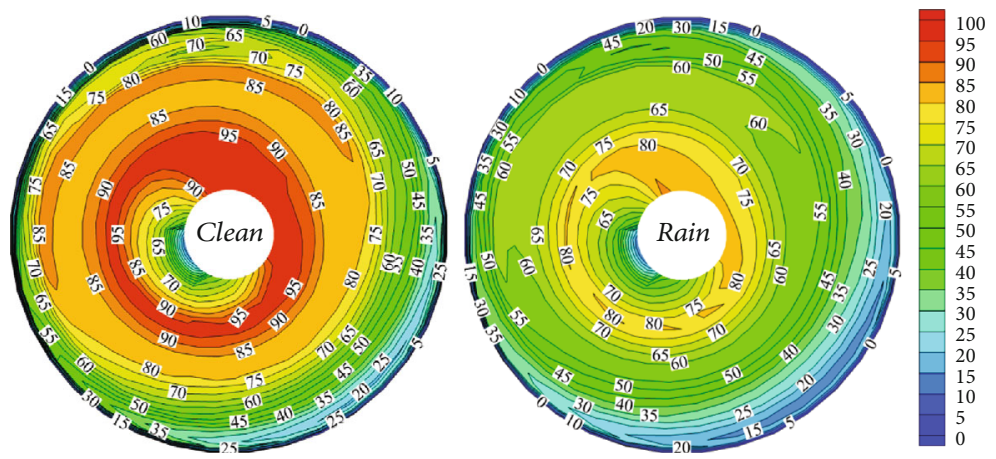

(b)

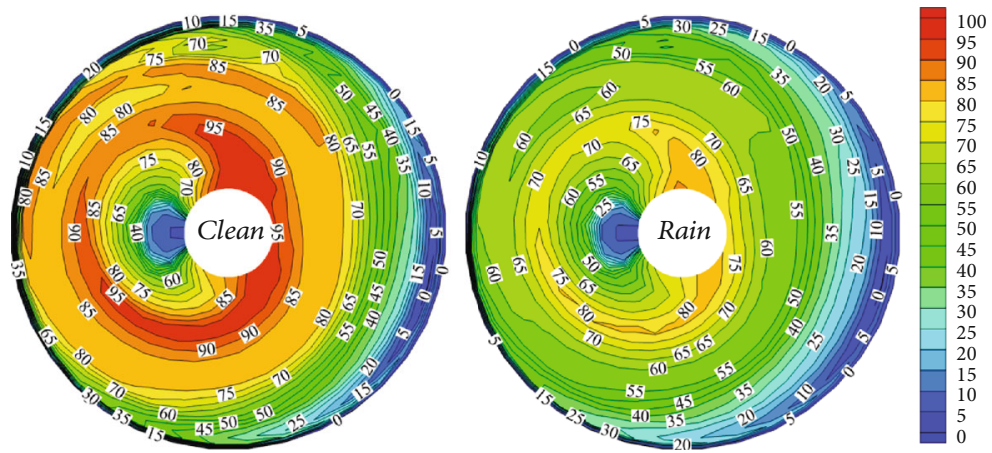

(c)
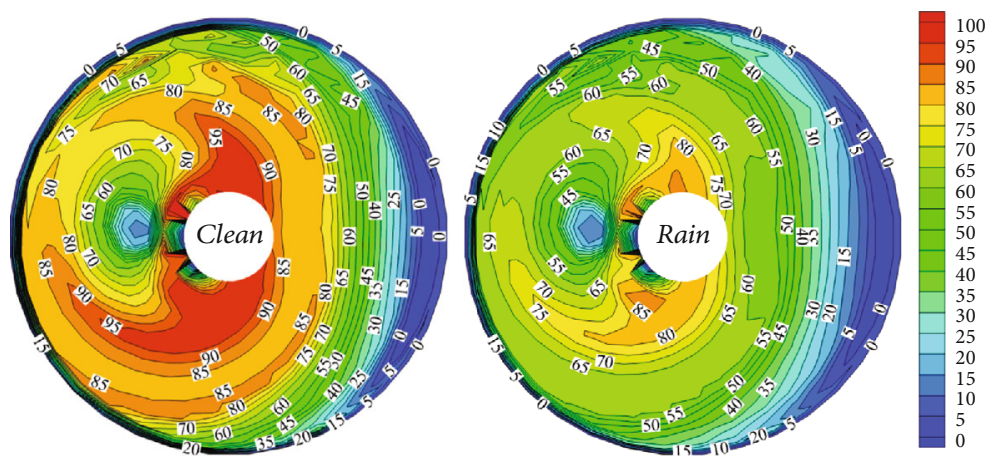

(d)

Figure 16: Continued. 

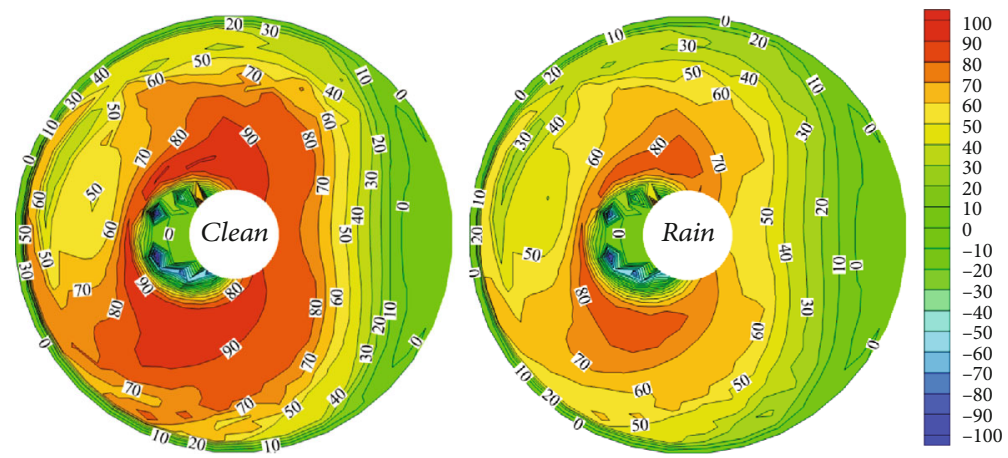

(e)

FIGURE 16: The lift-to-drag ratio distribution of the rotor disk at velocities of (a) 0 knots, (b) 40 knots, (c) 80 knots, (d) 120 knots, and (e) 160 knots.

(1) With the water film flowing to the trailing edge of the airfoil, $h$ would gradually increase. Furthering with the increase in the rain rate, $h$ would also increase

(2) The maximum value of $h$ is nearly close to $4 \mathrm{~mm}$ due to the large chord length of the NACA 0012 airfoil. This local thickness effect might affect the aerodynamic performance evidently

(3) The $\beta$ of the stagnation point of the airfoil leading edge reaches to a maximum, and the raindrop impinging area on the upper airfoil wall would be larger than that on the lower airfoil wall.

To validate the accuracy of the water film roughness, including the raindrop splash, Figure 11 shows the numerical results of the water film roughness of the NACA0012 airfoil in different rain rates. The CFD results are in good agreement with the reference data [27]. Some of the conclusions can be drawn that both the roughness due to craters and the roughness due to water waves increase to a certain extent with the increase in the rain rate.

3.2. Application Case. The water film flow of the SC1095 blade airfoil of UH-60A helicopter is numerically simulated. Figure 12 shows the local raindrop collection efficiency $(\beta)$ of the airfoil in different AOAs. It can be found that the raindrop impinging area on the airfoil wall gradually moves and diffuses from the upper airfoil wall to the lower airfoil wall with the increase in AOA. This might have a critical influence on the water film flow.

Figure 13 shows the coordinate view of the local water film thickness $(h)$ of the SC1095 blade airfoil in different AOAs from 0 deg to $20 \mathrm{deg}$, with 4 deg apart. Figure 14 shows the corresponding geometrical view. It can be found that the local water film thickness of the airfoil is very small, compared with the local water film thickness of the NACA 0012 airfoil in Figure 9. This is because the chord length of the SC1095 airfoil is so smaller than the chord length of the NACA 0012 airfoil in the simulation case. Some of the discussions can be drawn as follows:
(1) In the range of the AOA from $0 \mathrm{deg}$ to $8 \mathrm{deg}$, the water film is very thin and does not change evidently, the maximum thickness of the local water film is about $0.4 \mathrm{~mm}$, and the local water film thickness on the lower wall of the airfoil is about within $0.1 \mathrm{~mm}$

(2) When the AOA increases to $12 \mathrm{deg}$, the water film on the trailing edge of the upper airfoil wall begins to flow reversely which makes the local water film thickness increase evidently

(3) When the AOA continues to increase to $16 \mathrm{deg}$, the effect of the reverse pressure gradient becomes increasingly evident, which leads to the local water film thickness increasing sharply, making the aerodynamic shape of the blade airfoil seriously damaged and inevitably leading to the aerodynamic performance degradation

(4) When the AOA continues to increase to $20 \mathrm{deg}$, the local water film thickness decreases. Because the airfoil is completely in high AOA operational conditions, any slight change in the water film would cause serious damage to the aerodynamic performance of the airfoil.

The features of the water film flow on the rotor blade airfoil of UH-60A helicopters in different AOAs indicate that the stall of a helicopter rotor blade in the rain conditions will make the water film on the blade surface change dramatically, cause the aerodynamic geometry of the blade airfoil damaged, and degrade the aerodynamic performance, even probably causing the helicopter to encounter an unexpected flight accident.

Figure 15 shows the results of the water film roughness of the SC1095 airfoil in different AOAs, including the roughness due to craters and the roughness due to water waves. The results show that the water film roughness of the airfoil is about one order of magnitude smaller than that of the NACA0012 airfoil (Figure 11). This may be due to the effect of the different chord length of the airfoil (that is, the chord 
length of the SC1095 airfoil is $0.5273 \mathrm{~m}$ while the chord length of the NACA 0012 airfoil is $10 \mathrm{~m}$ ). Furthermore, both the water film roughness due to craters and water film roughness due to water waves have the trend of decreasing with the increase in the AOA, except for the case of $12 \mathrm{deg}$ AOA. These may be attributed to the obvious increase in the local water film thickness at the trailing edge of the upper wall of the airfoil at the AOA of $12 \mathrm{deg}$ (Figures 13 and 14), which leads to the increase in the averaging water film thickness and leads to the increase in the water roughness due to water waves. However, as the AOA continues to increase, the water film coverage area on the upper wall becomes smaller and smaller due to the effects of the reverse pressure gradient of the air flow. Thus, the water film roughness gradually decreases. This phenomenon might probably affect the aerodynamic performance of the airfoil and the rotor performance.

Table 2 shows the CFD simulation data related to aerodynamic performance degradation of the SC1095 blade airfoil in the rain conditions, including the variation of the lift coefficient and drag coefficient at different AOAs. These can be used as a data-driven basis relating to multiple working conditions of the rotating blades for further analysis of helicopter rotor performance degradation in the rain condition. It can be found that the maximum percentage decrease in lift coefficient is reached by $12.75 \%$ and the maximum percentage increase in drag coefficient by $26.51 \%$.

Table 3 shows the simulation results of the averaged liftto-drag ratio degradation of the rotor disk of UH-60A helicopter. It can be found that the maximum percentage decrease in the averaging lift-to-drag ratio of the rotor disk of UH-60A helicopter is reached by $26.39 \%$.

The detailed lift-to-drag ratio distribution of the rotor disk of UH-60A helicopter is calculated in trim state. Figure 16 presents the comparison of the lift-to-drag ratio distribution of the rotor disk before and after encountering rainfall at different flight velocities $(D X)$ of 0 knots, 40 knots, 80 knots, 120 knots, and 160 knots. These evidently indicate that the lift-to-drag ratio evidently drops when the helicopter rotor encounters rainfall.

\section{Conclusions}

Through the above research and analysis, we can draw the following conclusions:

(1) The comparison of these CFD results shows that the numerical method is correct and accurate, and it can be used to simulate the helicopter rotor in natural rainfall encounters

(2) The variation of AOA has a critical influence on the water film flow on the blade airfoil surface. The stall with a large AOA of the helicopter rotor blade in natural rainfall encounters will make the water film flow change dramatically, cause the aerodynamic geometry of the blade airfoil damaged, and degrade the aerodynamic performance, even probably causing the pilot to encounter an unexpected flight accident

(3) Because the CFD results show that the water film roughness of the SC1095 airfoil with $0.5273 \mathrm{~m}$ chord length is about one order of magnitude smaller than that of the NACA0012 airfoil with $10 \mathrm{~m}$ chord length, the variation of the chord length of the airfoil might dramatically affect the water film roughness due to craters and the water film roughness due to water waves. In addition, the water film roughness will increase with the increase in the rain rate, and it will decrease with the increase in AOA. These might probably affect the aerodynamic performance of the airfoil and the rotor performance

(4) Rainfall would dramatically degrade the airfoil/rotor aerodynamic performance. In the thunderstorm heavy rain with $R=1500 \mathrm{~mm} / \mathrm{h}$, the maximum percentage decrease in lift coefficient of SC1095 airfoil is reached by $12.75 \%$ and the maximum percentage increase in drag coefficient by $26.51 \%$. Furthermore, the maximum percentage decrease in averaging liftto-drag ratio of the UH-60A helicopter rotor disk is reached by $26.39 \%$.

\section{Data Availability}

The data used to support the findings of this study are available from the corresponding author upon request.

\section{Conflicts of Interest}

The authors declare that there is no conflict of interest regarding the publication of this article.

\section{References}

[1] Y. H. Cao, Z. L. Wu, and Z. Y. Xu, "Effects of rainfall on aircraft aerodynamics," Progress in Aerospace Sciences, vol. 71, pp. 85-127, 2014.

[2] R. V. Rhode, "Some effects of rainfall in flight of airplanes and on instrument indications," NASA, vol. TN-903, 1941.

[3] J. Luers and P. Haines, "Heavy rain influence on airplane accidents," Journal of Aircraft, vol. 20, no. 2, pp. 187-191, 1983.

[4] M. A. Dietenberger, P. A. Haines, and J. K. Luers, "Reconstruction of Pan Am New Orleans accident," Journal of Aircraft, vol. 22, no. 8, pp. 719-728, 1985.

[5] J. Mazon, J. I. Rojas, M. Lozano, D. Pino, X. Prats, and M. M. Miglietta, "Influence of meteorological phenomena on worldwide aircraft accidents, 1967-2010," Meteorological Applications, vol. 25, no. 2, pp. 236-245, 2018.

[6] O. W. K. Lee, "Preliminary investigation of effects of heavy rain on the performance of aircraft," NASA, vol. TM-83272, 1982.

[7] C. F. Hess and F. Li, Optical Technique to Study the Impact of Heavy Rain on Aircraft Performance, NASA-CR-177989, 1986.

[8] A. J. Bilanin, "Scaling laws for testing airfoils under heavy rainfall," Journal of Aircraft, vol. 24, no. 1, pp. 31-37, 1987.

[9] Z. L. Wu, Y. H. Cao, and M. Ismail, "Numerical simulation of airfoil aerodynamic penalties and mechanisms in heavy rain," 
International Journal of Aerospace Engineering, vol. 2013, 13 pages, 2013.

[10] W. Calarese and W. L. Hankey, Numerical Analysis of Rain Effects on an Airfoil, AIAA-84-0539, 1984.

[11] T. Wan and S. W. Wu, "Aerodynamic analysis under influence of heavy rain," Journal of Aeronautics, Astronautics and Aviation, vol. 41, no. 3, pp. 173-180, 2009.

[12] I. Aramendia, U. Fernandez-Gamiz, and A. Lopez-Arraiza, "Water droplets effects on an airfoil aerodynamic performance," International Journal of Mechanics, vol. 11, pp. 234241, 2017.

[13] T. Wan and S. P. Pan, "Aerodynamic efficiency study under the influence of heavy rain via two-phase flow approach," in Proceedings of the 27th International Congress of the Aeronautical Sciences, pp. 1-10, Nice, France, 2010.

[14] M. Ismail, Y. H. Cao, and A. Bakar, "Aerodynamic efficiency study of $2 \mathrm{D}$ airfoils and $3 \mathrm{D}$ rectangular wing in heavy rain via two-phase flow approach," in Proceedings of the Institution of Mechanical Engineers, Part G: Journal of Aerospace Engineering, vol. 228no. 7, pp. 1141-1155, 2014.

[15] M. Ismail, Y. H. Cao, Z. L. Wu et al., "Numerical study of aerodynamic efficiency of a wing in simulated rain environment," Journal of Aircraft, vol. 51, no. 6, pp. 2015-2023, 2014.

[16] H. Sharma, S. Vekaria, and S. Harshe, Computational Assessment of Rainfall Effects on Aircraft Aerodynamic Characteristics, AIAA-2015-3164, 2015.

[17] T. Wan, J. X. Lin, and H. C. Kuan, "Aerodynamic analysis of helicopter rotor blades in heavy rain condition," AIAA, vol. 2013-0653, 2013.

[18] K. D. Korkan, L. Dadone, and R. J. Shaw, "Helicopter rotor performance degradation in natural icing encounter," Journal of Aircraft., vol. 21, no. 1, pp. 84-85, 1984.

[19] X. Chen and Q. J. Zhao, "Numerical simulations for ice accretion on rotors using new three-dimensional icing model," Journal of Aircraft, vol. 54, no. 4, pp. 1428-1442, 2017.

[20] X. Chen, Q. J. Zhao, and G. Barakos, "Numerical analysis of aerodynamic characteristics of iced rotor in forward flight," AIAA Journal, vol. 57, no. 4, pp. 1523-1537, 2019.

[21] E. C. Hastings and L. M. Weinstein, "Preliminary indications of water film distribution and thickness on an aircraft in a water spray," NASA TM-85796, 1984.

[22] Z. L. Wu and Y. H. Cao, "Aerodynamic study of aerofoil and wing in simulated rain environment via a two-way coupled eulerian-lagrangian approach," The Aeronautical Journal, vol. 118, no. 1204, pp. 643-668, 2014.

[23] T. Wan, An investigation of quad-rotor aircraft performance under gust wind and heavy rain impacts, AIAA 2020-1735, 2020.

[24] T. Wan, Aerodynamic Analysis of TRAP Wing Under Influence of Heavy Rain Effects, AIAA 2020-1984, 2020.

[25] W. Johnson, Helicopter Theory, Princeton University Press, Princeton, 1980.

[26] J. S. Marshall and W. M. Palmer, "The distribution of raindrops with size," Journal of Meteorology, vol. 5, no. 4, pp. 165-166, 1948.

[27] P. A. Haines and J. K. Luers, Aerodynamic penalties of heavy rain on a landing aircraft, NASA Contractor Report 156885, 1982.

[28] G. M. Bezos, R. E. Jr, and G. L. Dunham Jr., Wind Tunnel Aerodynamic Characteristics of a Transport-type Airfoil in a
Simulated Heavy Rain Environment, NASA Technical Paper 3184, 1992.

[29] M. Snellen, O. J. Boelens, and H. W. M. Hoeijmakers, A Computational Method for Numerically Simulating Ice Accretion, AIAA 1997-2206, 1997.

[30] B. P. Leonard, "A stable and accurate convective modeling procedure based on quadratic upstream interpolation," Computer Methods in Applied Mechanics and Engineering, vol. 19, no. 1, pp. 59-98, 1979.

[31] R. E. Dirling, "A method for computing roughwall heat transfer rates on re-entry nosetips," in Proceedings of the 8th AIAA Thermophysics Conference, Palm Springs, Calif, USA, 1973.

[32] W. C. Mackin and G. J. Metaxas, "Splashing of drops on liquid layers," Journal of Applied Physics, vol. 47, no. 9, pp. 39633970, 1976.

[33] J. J. Howlett, UH-60A black hawk engineering simulation program: volume I - mathematical model, NASA CR 166309, 1981.

[34] Y. H. Cao, G. Z. Li, and G. Zhong, "Tandem helicopter trim and flight characteristics in the icing condition," Journal of Aircraft, vol. 47, no. 5, pp. 1559-1569, 2010.

[35] Y. H. Cao, G. Z. Li, and R. A. Hess, "Helicopter flight characteristics in icing conditions," The Aeronautical Journal, vol. 116, no. 1183, pp. 963-979, 2012.

[36] G. Z. Li and Y. H. Cao, "Numerical simulation of the wake generated by a helicopter rotor in icing conditions," Fluid Dynamics \& Materials Processing, vol. 17, no. 2, pp. 235-252, 2021. 